\title{
How levosimendan can improve renal function?
}

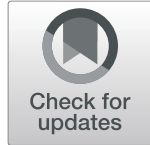

Patrick M. Honore*, Leonel Barreto Gutierrez, Sebastien Redant, Keitiane Kaefer, Andrea Gallerani and David De Bels

This comment refers to the article available at https://doi.org/10.1186/s13054-017-1848-1.

In recent years, several studies have addressed the positive effects of levosimendan upon renal function. We sought to summarize the recent findings in order to understand by which mechanism levosimendan is improving renal function. In acute decompensated heart failure, levosimendan has an immediate renoprotective effect by increasing renal blood flow (RBF) through selective renal arterial and venous vasodilation [1]. In a recent randomized controlled study (RCT) comparing dobutamine and levosimendan in cardio-renal syndrome (CRS), Fedele et al. [2] were able to reproduce the results of Chen et al. [1] by measuring RBF through the renal artery $[1,2]$. Fedele et al. and Chen et al. found that levosimendan increased RBF $[1,2]$. But increasing RBF alone is not enough. Levosimendan and dobutamine exerted differential effects on glomerular filtration ratio (GFR). Both inotropic agents induced a renal vasodilatory effect accompanied by an increase in RBF, but while dobutamine does not change GFR, levosimendan increases GFR significantly [3]. Levosimendan preferentially causes a vasodilation of the afferent arterioles while dobutamine induces a balanced vasodilation of both afferent and efferent arterioles, thereby increasing RBF, while maintaining a constant glomerular filtration pressure [3]. Obviously, an isolated increase in GFR could jeopardize oxygenation of the medulla, which is sensitive to ischemia, given the highly oxygendemanding sodium reabsorption process. For levosimendan, however, this is less likely to occur because it causes a balanced increase in GFR and renal oxygen delivery, as shown by the maintained renal oxygen consumption and extraction [4]. Last, a rise in central venous pressure (CVP) is an important predictor of renal dysfunction in heart failure patients [5]. Elevated CVP will increase renal venous backpressure and thus

\footnotetext{
* Correspondence: Patrick.Honore@CHU-Brugmann.be

ICU Department, Centre Hospitalier Universitaire Brugmann- Brugmann University Hospitals, Place Arthur Van Gehuchtenplein, 4, 1020 Brussels, Belgium
}

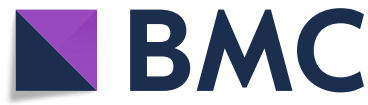

(c) The Author(s). 2019 Open Access This article is distributed under the terms of the Creative Commons Attribution 4.0 International License (http://creativecommons.org/licenses/by/4.0/), which permits unrestricted use, distribution, and reproduction in any medium, provided you give appropriate credit to the original author(s) and the source, provide a link to the Creative Commons license, and indicate if changes were made. The Creative Commons Public Domain Dedication waiver (http://creativecommons.org/publicdomain/zero/1.0/) applies to the data made available in this article, unless otherwise stated. decrease renal perfusion pressure and impair renal function [5]. Compared to dobutamine, levosimendan could further reduce CVP and by this end improve renal function also, but this is not supported by the findings of Lannemyr et al. because both inotropic agents reduced CVP to a similar extent [3]. In conclusion, it is too simplistic to rely upon RBF to expect an improvement in renal function. An increase in RBF has to be accompanied by an increase in GFR but not at the cost of medullary hypoxemia, which is not the case with levosimendan. Effects on the reduction of CVP might also play a role. Finally, luxurious oxygenation of the cortex as induced by dopamine and dobutamine is completely useless for the kidney function, and again, the puzzle of improving renal function is far more complex.

\section{Abbreviations \\ AKI: Acute kidney injury; RCT: Randomized controlled study: RBF: Renal blood flow; GFR: Glomerular filtration ratio; CVP: Central venous pressure}

\section{Acknowledgements}

None.

Authors' contributions

PMH and DDB designed the paper. All authors participated in drafting and reviewing. All authors read and approved the final version of the manuscript.

\section{Funding}

None.

Availability of data and materials

Not applicable.

Ethics approval and consent to participate Not applicable.

Consent for publication Not applicable.

Competing interests

The authors declare that they have no competing interests. 
Received: 26 September 2019 Accepted: 9 October 2019

Published online: 29 October 2019

\section{References}

1. Chen $\mathrm{QH}$, Zheng RQ, Lin H, Shao J, Yu JQ, Wang HL. Effect of levosimendan on prognosis in adult patients undergoing cardiac surgery: a meta-analysis of randomized controlled trials. Crit Care. 2017;21(1):253. https://doi.org/10. 1186/s13054-017-1848-1 Review.

2. Fedele F, Bruno N, Brasolin B, et al. Levosimendan improves renal function in acute decompensated heart failure: possible underlying mechanisms. Eur J Heart Fail. 2014;16(3):281-8.

3. Lannemyr L, Ricksten SE, Rundqvist B, Andersson B, Bartfay SE, Ljungman C, et al. Differential effects of levosimendan and dobutamine on glomerular filtration rate in patients with heart failure and renal impairment: a randomized double blind controlled trial. J Am Heart Assoc. 2018;7(16): e008455. https://doi.org/10.1161/JAHA.117.008455.

4. Redfors B, Bragadottir G, Sellgren J, Sward K, Ricksten SE. Dopamine increases renal oxygenation: a clinical study in post-cardiac surgery patients. Acta Anaesthesiol Scand. 2010;54:183-90.

5. Chen X, Wang X, Honore PM, Spapen HD, Liu D. Renal failure in critically ill patients, beware of applying (central venous) pressure on the kidney. Ann Intensive Care. 2018;8(1):91. https://doi.org/10.1186/s13613-018-0439-x.

\section{Publisher's Note}

Springer Nature remains neutral with regard to jurisdictional claims in published maps and institutional affiliations. 